\title{
PERANCANGAN SISTEM PENGIRIMAN BARANG PADA CV. HELIOS VISI ABADI BERBASIS JAVA NETBEANS
}

\author{
Ramadhan Angga Bayu ${ }^{1}$, Ulfa Pauziah ${ }^{2}$, Luh Putu Widya Adnyani ${ }^{3}$ \\ ${ }^{1,2,3}$ Teknik Informatika, FTIK, Universitas Indraprasta PGRI \\ Jalan Raya Tengah No 80, Kelurahan Gedong, Pasar Rebo,Jakarta Timur \\ 1ramadhananggab28@gmail.com, 2 ulfapauziah9@gmail.com, ${ }^{3}$ aluhputuwidya@gmail.com
}

\begin{abstract}
ABSTRAK
Kacamata saat ini merupakan kebutuhan dari orang yang mengunakan kacamata, selain untuk membantu dalam penglihatan juga dapat digunakan untuk fasion. Sayangnya banyak orang yang tidak banyak memiliki waktu dan mengabaikan pentingnya control mata. Karena kesibukan yang ada tidak adanya waktu untuk pergi ke dokter atau optik untuk mengontrolkan matanya dan membeli kacamata yang baru untuk menggantikan kacamata yang lama. Permasalahan yang terdapat pada CV. Helios Visi Abadi adalah penyimpanan data pembelian secara online masih dilakukan secara manual, oleh sebab itu dibutuhkan sebuah sistem yang dapat mendata daftar-daftar data tersebut dengan melakukan perbaikan mengolah sebuah sistem yang dapat mengolah data. Tujuan dari penelitian ini adalah untuk membantu perusahaan dalam pengiriman barang. Metodologi penelitian yang digunakan dalam pencarian data yang dibutuhkan dalam penelitian ini yaitu teknik pengumpulan data. Program ini dibuat dengan bahasa pemrograman Java NetBeans 8.0.2 digunakan untuk mendapatkan informasi mengenai bagaimana menjaga keamanan data yang sudah disimpan di localhost, dan data databasenya disimpan di MySQL. setelah penulis merancang dan menganalisa program sistem pengiriman barang ini, berdasarkan penelitian dari hasil berupa aplikasi sistem pengiriman barang yang dapat digunakan untuk mendapatkan informasi mengenai bagaimana menjaga keamanan data yang disimpan, dan data databasenya akan disimpan di MySQL.
\end{abstract}

Kata Kunci: Pengiriman barang, Helios, Java, MySQL

\begin{abstract}
Glasses are currently a necessity for people who use glasses, apart from helping in vision, they can also be used for fashion. Unfortunately many people do not have much time and ignore the importance of eye control. Due to the busy schedule, there is no time to go to the doctor or optician to get his eyes checked and buy new glasses to replace the old ones. The problems contained in the CV. Helios Visi Abadi is online purchasing data storage is still done manually, therefore we need a system that can record these data lists by making improvements to process a system that can process data. The purpose of this research is to assist companies in shipping goods. The research methodology used in the search for the data needed in this research is data collection techniques. This program was created with the Java NetBeans 8.0.2 programming language used to obtain information about how to maintain the security of data that has been stored on localhost, and database data stored in MySQL. after the author designed and analyzed the delivery system program, based on research from the results in the form of a delivery system application that can be used to obtain information about how to maintain the security of the stored data, and the database data will be stored in MYSQL.
\end{abstract}

Key Word: Freight Forwarding, Helios, Java, MySQL

\section{PENDAHULUAN}

Kacamata saat ini merupakan kebutuhan dari orang yang mengunakan kacamata, selain untuk membantu dalam penglihatan juga dapat digunakan untuk fasion. Sayangnya banyak orang yang tidak banyak memiliki waktu dan mengabaikan pentingnya control mata. Karena kesibukan yang ada tidak adanya waktu untuk pergi ke dokter atau optik untuk mengontrolkan matanya dan membeli kacamata yang baru untuk menggantikan kacamata yang lama. Maka dari itu banyak sekali orang yang memakai kacamata yang lama hingga bertahun tahun. Itu dikarenakan tidak memiliki waktu untuk membeli yang baru (Almasyariqi et al., 2018).

Saat ini perkembangan teknologi sudah mengarah kepada hal yang jauh lebih global seperti penggunaan web pada sebuah perusahaan. Perusahaan transportasi merupakan salah satu diantaranya, melakukan pengiriman barang dari perkotaan hingga pedesaan, dari sabang hingga merauke. 
Perusahaan tersebut tentunya membutuhkan sistem informasi manajemen baik dalam pengelolaan data, informasi atau profil perusahaan, hingga menampilkan biaya dan melakukan pemesanan jasa pengiriman barang yang keseluruhan aktifitasnya dapat dilakukan menggunakan halaman web. Oleh karena itu kebutuhan akan web profil atau manajemen saat ini sangatlah mendesak untuk kemajuan perusahaan. Untuk itu perlu dilakukan perancangan sistem informasi jasa pengiriman barang yang hanya dilakukan menggunakan atau berbasis web. Sehingga dapat mengakomodir kebutuhan akan permintaan jasa pengiriman barang yang semakin meningkat setiap waktunya (Dhika et al., 2016).

Kegiatan yang ada pada bisnis ekspedisi pengiriman barang salah satunya adalah administrasi dalam pengelolaan data pengiriman barang. Kendala yang terjadi yaitu kehilangan data karena kurang tertib administrasi, kekeliruan data atau kurang lengkapnya data pengiriman barang akan membuat jasa ekspedisi ini terhambat dalam pengiriman barang. Pembagian kerja masingmasing kurir merupakan hal rumit sehingga bagian admin harus mengetahui kurir yang dapat melakukan kegiatan pengiriman barang. Pengiriman barang bisa terjadi tepat waktu atau jika terjadi kendala maka bisa menyebakan lama dalam pengiriman. Hal ini membuat konsumen ingin mengetahui tracking dari pengiriman barangnya jika belum menggunakan sistem maka proses pelacakan barang akan sulit dilakukan. Hal inilah yang menyebabkan seringnya terjadi kesalahpahaman antara perusahaan dan kurir ataupun dengan operator yang dapat mengakibatkan kerugian waktu dan biaya.

Dalam era globalisasi, teknologi menjadi kebutuhan dalam berbisnis usaha, karena adanya teknologi dapat memudahkan pengusaha dalam pengembangan dan pengelolaan bisnisnya. Oleh karena itu teknologi dibutuhkan dalam menjalankan bisnis usaha optik online, yaitu menambah sistem pengiriman barang. Maka penulis mengambil topik dan menyusun skripsi dengan judul "Perancangan Sistem Pengiriman Barang Pada CV. Helios Visi Abadi Berbasis Java Netbeans".
Adapun tujuan dari penelitian tersebut adalah mengidentifikasi sistem pengiriman barang yang sedang berjalan pada CV. Helios Visi Abadi. Mengumpulkan data-data perancangan sistem pengiriman barang yang dibutuhkan sesuai dengan perancangan sistem pengiriman barang yang akan dibangun. Dan merancang sistem pengiriman barang berbasis netbeans pada CV. Helios Visi Abadi secara sistemastis, terstruktur, dan terarah sehingga dapat digunakan oleh CV. Helios Visi Abadi untuk mengatasi ketidakefektifan dan efisiensi sistem manual yang digunakan saat ini.

Manfaat yang diharapkan dalam penelitian ini adalah memperoleh pengetahuan yang lebih luas dalam bidang pengiriman barang berbasis java netbeans. Serta bagi mitra dapat meningkatkan penjualan yang lebih luas dengan menggunakan aplikasi ini.

Perancangan mempunyai 2 maksud, yaitu untuk memenuhi kebutuhan kepada pemakai sistem dan untuk memberikan gambaran yang jelas kepada pemogram komputer dan ahliahli teknik lainnya yang terlibat (Mujiati, 2013).

Perancangan adalah sebuah proses untuk mendefinisikan sesuatu yang akan dikerjakan dengan menggunakan teknik yang bervariasi serta didalamnya melibatkan deskripsi mengenai arsitektur serta detail komponen dan juga keterbatasan yang akan dialami dalam proses pengerjaannya (Setiyanto et al., 2019).

Sistem adalah sekelompok elemen-elemen yang terintegrasi dengan tujuan tujuan yang sama untuk mencapai tujuan. Sistem juga merupakan suatu jaringan kerja dari prosedur yang saling berhubungan, terkumpul bersama-sama untuk melakukan suatu kegiatan atau untuk tujuan tertentu (Dewi \& Malfiany, 2017).

Sistem adaah kumpulan dari bagian bagian atau hal-hal yang berkaitan dan beroperasi atau bekerja secara bersama-sama untuk mencapai satu atau lebih tujuan atau sasaran (Gunawan, 2018).

Aplikasi adalah penggunaan atau penerapan suatu konsep yang menjadi pokok pembahasan. Aplikasi dapat diartikan juga 
sebagai program komputer yang dibuat untuk menolong manusia dalam melaksanakan tugas tertentu (Sukisno \& Wuni, 2017).

Netbeans adalah aplikasi Integrated Development Environment (IDE) yang berbasiskan Java Menurut (Yulisma, 2020) Netbeans Merupakan Sebuah aplikasi Integrated Development Environment (IDE) yang Menggunakan Bahasa Pemograman Java dari Sun Microsystems yang berjalan diatas swing.

Xampp adalah sebuah software web browser yang di dalamnya sedah tersedia database server MySQL dan support php programming. Xampp merupakan software yang mudah digunakan, gratis, dan mendukung instalasi di Linux dan Windows (Sukisno \& Wuni, 2017).

MySQL adalah program database server yang mampumenerima dan mengirimkan datanya dengan sangat cepat, multi user serta menggunakan perintah standa SQL (Structured Query Language) (Rahmawita \& Fazri, 2018).

\section{METODE PENELITIAN}

Metode pengumpulan data yang dilakukan oleh peneliti untuk mendapatkan data-data dan informasi untuk mendukung penyempurnaan hasil dari penelitian ini, antara lain:

\section{a. Studi Lapangan (Field Research)}

\section{1) Survey}

Penulis melakukan survey ke Klinik Pratama Permata Medika dangan tujuan untuk melihat tempat dan mengumpulkan data.

\section{2) Wawancara}

Wawancara merupakan suatu teknik pengumpulan data yang dilakukan dengan cara tanya jawab antara penanya (interviewer) dengan penjawab (responden) (Farhan, 2020).

\section{3) Observasi}

Metode pengumpulan data yang dilakukan dengan cara pengamatan langsung dilapangan tempat kegiatan yang diteliti yaitu pada CV. Helios Visi Abadi.

\section{HASIL DAN PEMBAHASAN}

Aturan sistem yang diusulkan pada CV. Helios Visi Abadi adalah sebagai berikut:

1. Proses pendataan data petugas Setiap petugas yang bertugas akan didata sesuai dengan petugas yang sedang bertugas saat itu.

2. Proses pendataan data jenis paket Setiap paket yang dikirim akan di data sesuai paket yang akan dikirim.

3. Proses pendataan data pengirim Setiap pengirim yang ingin mengirimkan barang akan di data sesuai dengan data pengirim.

4. Proses pendataan data pengiriman barang

Setiap barang yang ingin dikirim akan didata secara menyeluruh pada proses data pengiriman barang agar dapat dilihat secara menyeluruh.

5. Proses laporan

Petugas harus mencetak laporan data petugas, jenis paket dan data pengirim untuk diserahkan kepada direktur operasional.

Berikut ini merupakan penggambaran tentang sistem yang diusulkan pada sistem pengiriman barang pada CV. Helios Visi Abadi secara keseluruhan dalam bentuk diagram konteks.

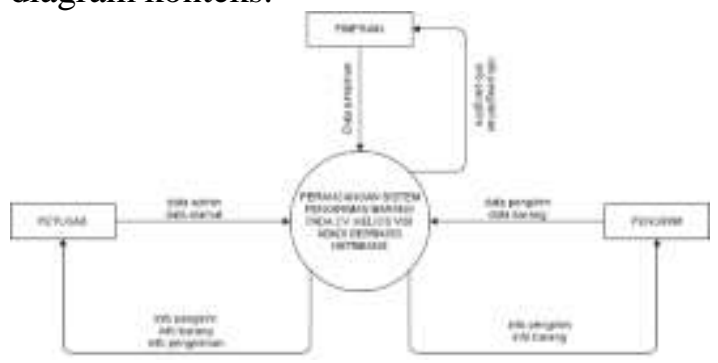

Gambar 1. Diagram Konteks Sistem Pengiriman Barang Pada CV. Helios Visi Abadi

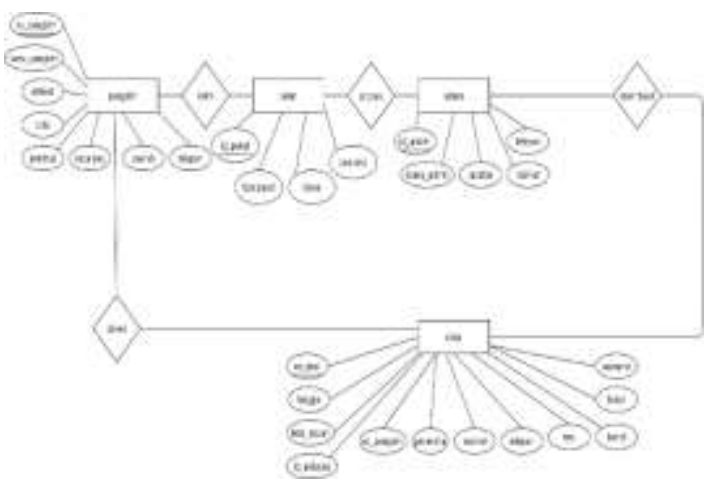

Gambar 2. Entity Relationship Diagram (ERD) Sistem Pengiriman Barang Pada CV. Helios Visi Abadi 
Selanjutnya penulis membuat aplikasi dengan menggunakan Java berbasis netbeans dan database mysql. Berikut ini adalah tampilan dari aplikasi sistem pengiriman barang pada CV. Helios Visi Abadi.

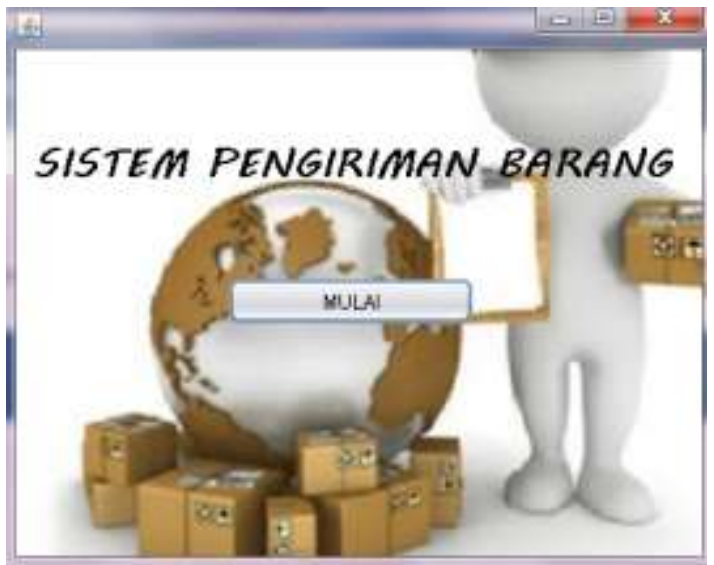

Gambar 3. Tampilan Halaman Utama

Pada halaman utama terdapat tombol mulai untuk memulai program sistem pengiriman barang ini.

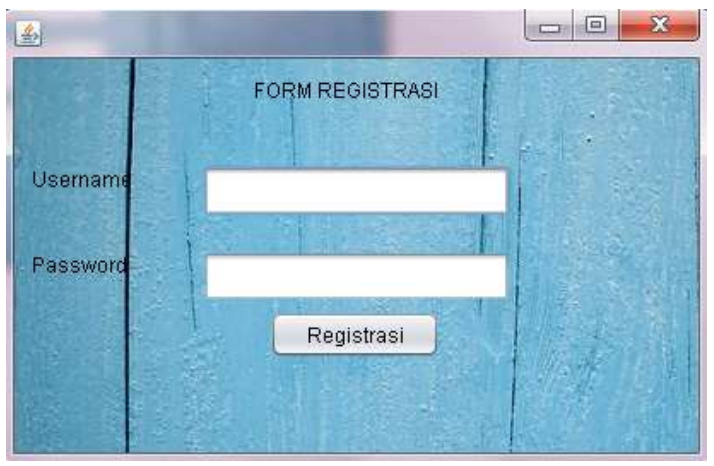

Gambar 4. Tampilan Form Login

Pada Form Registrasi ini petugas wajib mendaftarkan username dan password untuk dapat mengakses aplikasi ini.

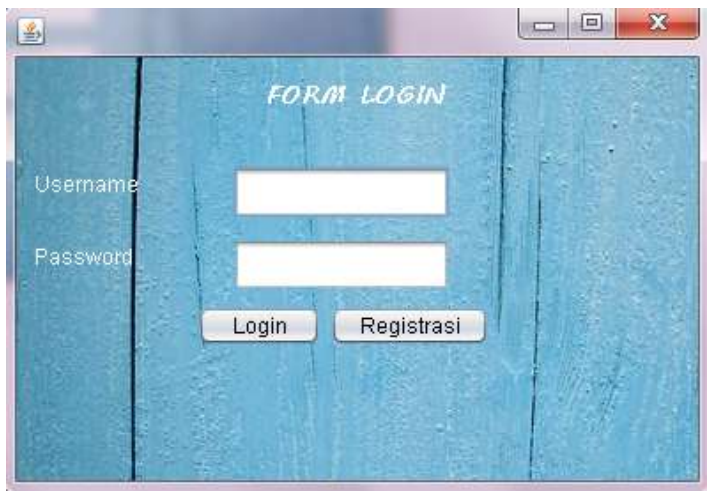

Gambar 5. Tampilan Form Login
Pada form login pengguna wajib memasukan username dan password yang telah didaftarkan melalui form registrasi untuk masuk kedalam menu utama pada sistem pengiriman barang ini.

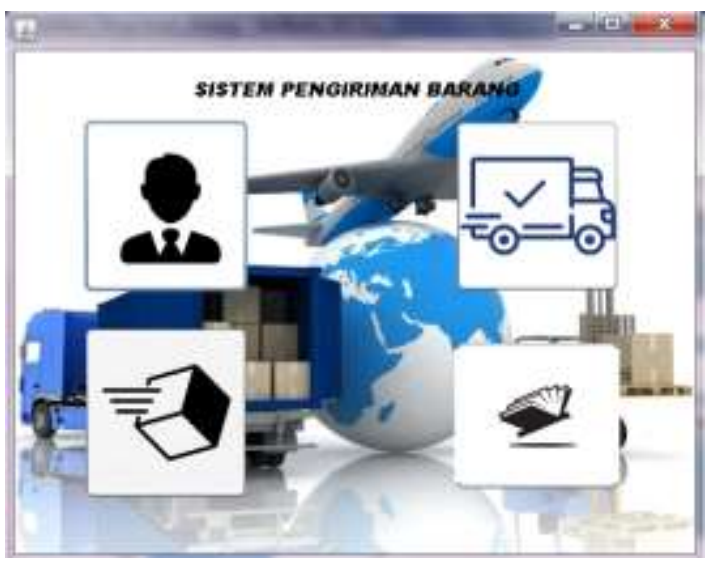

Gambar 6. Tampulan Form Menu Utama

Pada form menu utama ini terdiri dari menu data petugas, menu data jenis paket, menu data pengirim, dan manu data pengiriman barang.

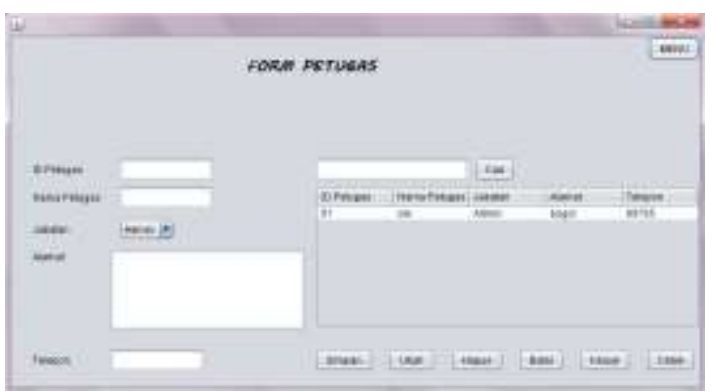

Gambar 7. Tampilan Form Petugas

Pada form petugas ini terdapat beberapa tombol yang terdiri dari tombol simpan yaitu untuk menyimpan data petugas kedalam database. Tombol ubah digunakan untuk merubah data yang telah di input, tombol hapus berfungsi ketika petugas ingin penghapus data yang telah di input, tombol batal untuk membatalkan semua data yang sedang di input oleh petugas, tombol cari untuk mencari data yang telah di input oleh petugas kedalam data table. Tombol menu untuk kembali ke menu utama, tombol keluar untuk keluar dari aplikasi tersebut, dan tombol cetak untuk mencetak laporan hasil dari inputan data petugas tersebut. 


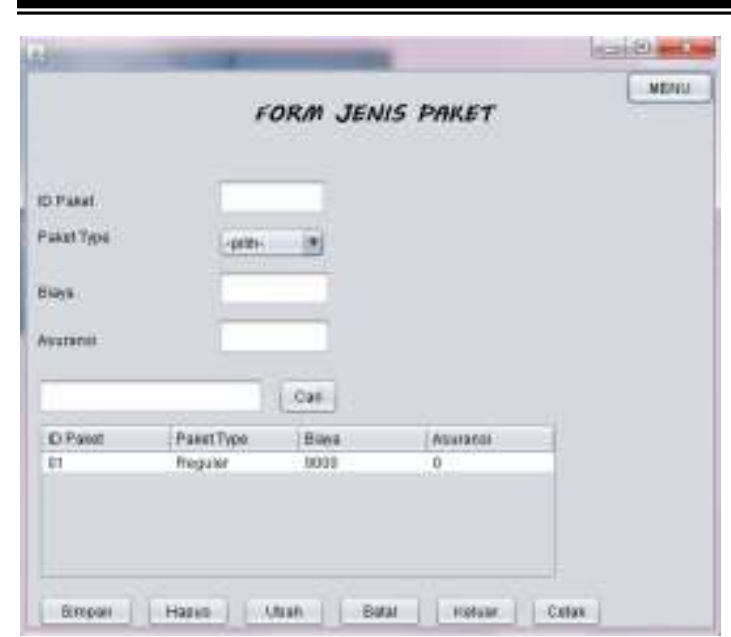

Gambar 8. Tampilan Form Jenis Paket

Pada form jenis paket ini terdapat beberapa tombol yang terdiri dari tombol simpan yaitu untuk menyimpan data petugas kedalam database. Tombol ubah digunakan untuk merubah data yang telah di input, tombol hapus berfungsi ketika petugas ingin penghapus data yang telah di input, tombol batal untuk membatalkan semua data yang sedang di input oleh petugas, tombol cari untuk mencari data yang telah di input oleh petugas kedalam data table. Tombol menu untuk kembali ke menu utama, tombol keluar untuk keluar dari aplikasi tersebut, dan tombol cetak untuk mencetak laporan hasil dari inputan data jenis paket tersebut.

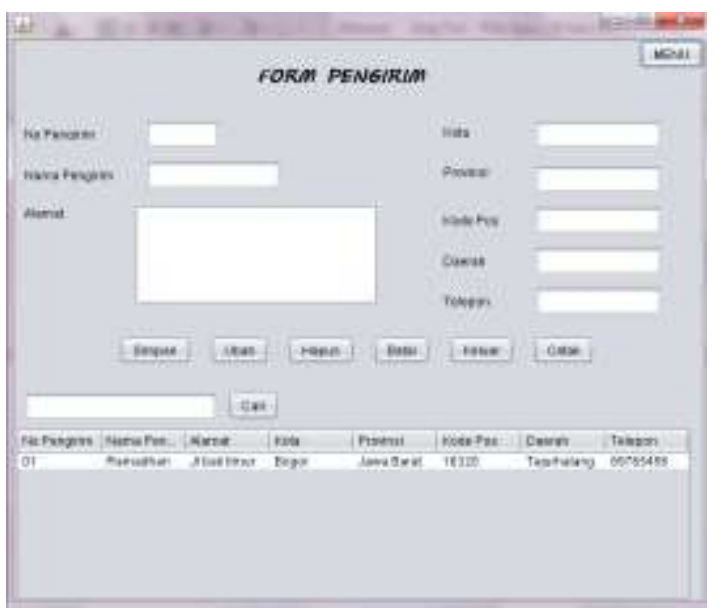

Gambar 9. Tampilan Form Pengirim

Pada form pengirim ini terdapat beberapa tombol yang terdiri dari tombol simpan yaitu untuk menyimpan data petugas kedalam database. Tombol ubah digunakan untuk merubah data yang telah di input, tombol hapus berfungsi ketika petugas ingin penghapus data yang telah di input, tombol batal untuk membatalkan semua data yang sedang di input oleh petugas, tombol cari untuk mencari data yang telah di input oleh petugas kedalam data table. Tombol menu untuk kembali ke menu utama, tombol keluar untuk keluar dari aplikasi tersebut, dan tombol cetak untuk mencetak laporan hasil dari inputan data pengirim tersebut.

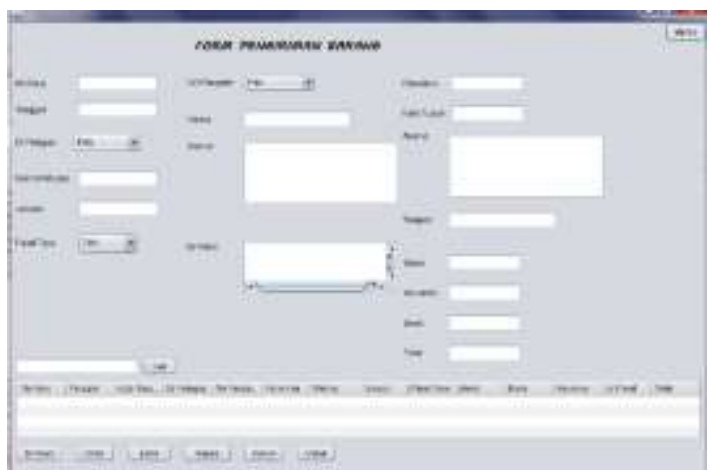

Gambar 10. Tampilan Form Pengiriman Barang

Pada form pengiriman barang ini terdapat beberapa tombol yang terdiri dari tombol simpan yaitu untuk menyimpan data petugas kedalam database. Tombol ubah digunakan untuk merubah data yang telah di input, tombol hapus berfungsi ketika petugas ingin penghapus data yang telah di input, tombol batal untuk membatalkan semua data yang sedang di input oleh petugas, tombol cari untuk mencari data yang telah di input oleh petugas kedalam data table. Tombol menu untuk kembali ke menu utama, tombol keluar untuk keluar dari aplikasi tersebut, dan tombol cetak untuk mencetak laporan hasil dari inputan data pengiriman barang tersebut.

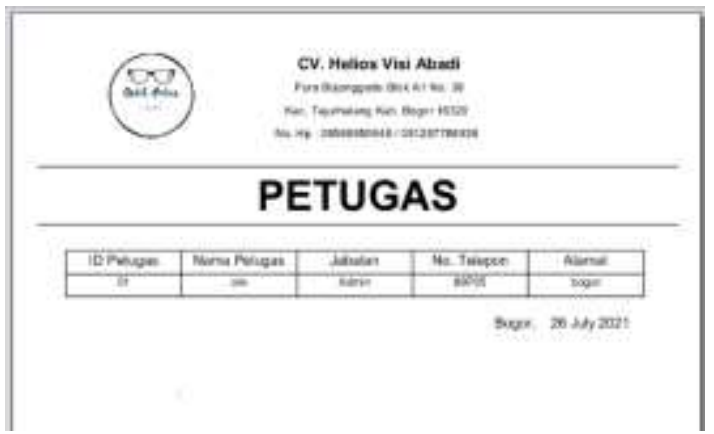

Gambar 11. Tampilan Laporan Data Petugas

Untuk menampilkan laporan petugas pada CV. Helios Visi Abadi. 


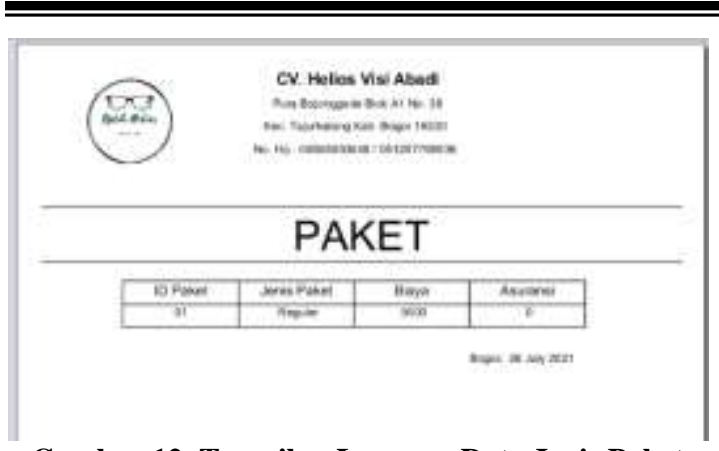

Gambar 12. Tampilan Laporan Data Jenis Paket

Untuk menampilkan laporan jenis paket pada CV. Helios Visi Abadi.

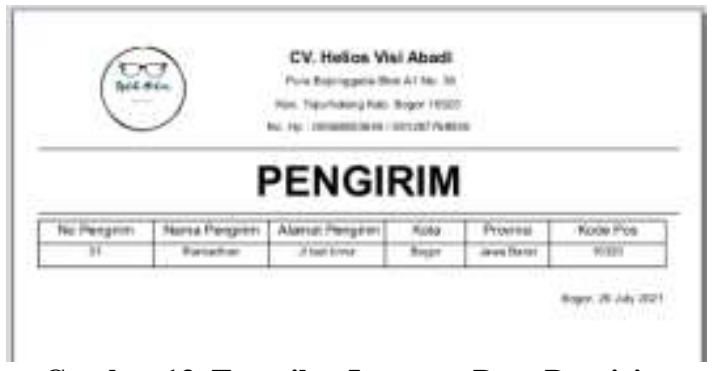

Gambar 13. Tampilan Laporan Data Pengirim

Untuk menampilkan laporan pengirim pada CV. Helios Visi Abadi.

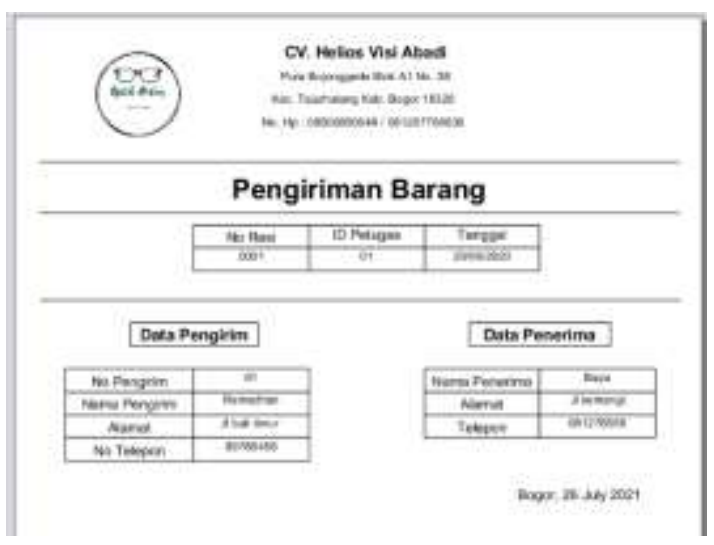

Gambar 14. Tampilan Laporan Data Pengiriman Barang

Untuk menampilkan laporan pengiriman barang pada CV. Helios Visi Abadi.

\section{SIMPULAN DAN SARAN}

Berdasarkan hasil pembahasan yang telah diuraikan, maka penulis dapat menarik kesimpulan sebagai berikut:

a) Dengan dirancangnya perancangan sistem pengiriman barang pada CV. Helios Visi Abadi, segala pengiriman barang dapat dilakukan lebih efektif dan efisien sehingga dapat membantu karyawan dalam mengirim barang. b) Dengan dirancangnya aplikasi ini pengolahan data akan lebih akurat dan detail sehingga kekeliruan data pengiriman barang dapat diminimalisir, serta membantu mempermudah pemeriksaan data secara berkala.

c) Dengan adanya aplikasi ini akan membantu pembuatan laporan pengiriman barang agar lebih efektif dan efisien untuk setiap prosesnya, serta hasil penyajian laporan yang akan lebih baik.

Sejalan dengan sistem usulan yang penulis buat, maka demi tercapainya tujuan dan sasaran yang diharapkan, maka penulis dapat memberi saran sebagai berikut:

1. Setiap data pengiriman yang telah dibuat diharapkan dapat digunakan secara optimal agar dapat membantu mempermudah dalam setiap pengiriman barang di CV. Helios Visi Abadi.

2. Diharapkan untuk kedepannya CV. Helios Visi Abadi dapat mengevaluasi apa saja hal yang dibutuhkan dalam pengiriman barang yang belum disediakan di aplikasi ini, sehingga untuk kedepannya perlu adanya pengembangan, penambahan fitur dalam aplikasi agar lebih lengkap dan mempermudah setiap proses yang dibutuhkan oleh CV. Helios Visi Abadi.

\section{DAFTAR PUSTAKA}

Almasyariqi, M. R., Rani, S., \& Suranto, B. (2018). Rancang Bangun Aplikasi Berbasis Augmented Reality untuk Virtual Fitting Room Frame Kacamata. Seminar Nasional Aplikasi Teknologi Informasi (SNATi), O(0).

Dewi, I. R., \& Malfiany, R. (2017). Perancangan Sistem Informasi Administrasi Pembayaran Pada Sdit Lampu Iman Karawang Berbasis Visual Basic 6.0. Jurnal Interkom: Jurnal Publikasi Ilmiah Bidang Teknologi Informasi Dan Komunikasi, 12(2), 4-12. https://doi.org/10.35969/interkom.v12i2 .5

Dhika, H., Lukman, L., \& Fitriansyah, A. (2016). Perancangan Sistem Informasi Jasa Pengiriman Barang Berbasis Web. Simetris : Jurnal Teknik Mesin, Elektro Dan Ilmu Komputer, 7(1). https://doi.org/10.24176/simet.v7i1.487

Farhan, M. (2020). Perancangan Sistem Inventory dan Penjualan Pakaian di 
Konveksi Aulia Collection. Jurnal Riset Dan Aplikasi Mahasiswa Informatika (JRAMI), $1(02)$. https://doi.org/10.30998/jrami.v1i02.23 4

Gunawan, E. (2018). Sistem Akuntansi Pembelian Barang Dagangan Pada Koperasi Maju Bersama Medan. 7(1), 97.

Hanik Mujiati, S. (2013). Analisis Dan Perancangan Sistem Informasi Stok Obat Pada Apotek Arjowinangun. Indonesian Jurnal on Computer Science - Speed (IJCSS) FTI UNSA, 9330(2), 16.

Rahmawita, M., \& Fazri, I. (2018). Aplikasi Peramalan Penjualan Obat Menggunakan Metode Least Squaredi Rumah Sakit Bhayangkara. Jurnal Ilmiah Rekayasa Dan Manajemen Sistem Informasi, 4(2), 201. https://doi.org/10.24014/rmsi.v4i2.5685

Setiyanto, R., Nurmaesah, N., \& Rahayu, N. S. A. (2019). Perancangan Sistem Informasi Persediaan Barang Studi Kasus di Vahncollections Rudi. Jurnal Sisfotek Global, 9(1), 137-142.

Sukisno, \& Wuni, W. F. (2017). Analisa Dan Perancangan Sistem Informasi Tracking Acuan Quality Departemen Brushing Berbasis Web Di PT. Indotaichen Textile Industry. Journal of Informatics Engineering, 5(1), 43-51.

Yulisma, M. (2020). Aplikasi Laporan Arus Kas Pada Pt. Saritama Cipta Usaha Bandar Lampung. Onesismik, 4(1), 3037. 